\title{
Synthesis, characterization and electrical properties of visible-light-driven Pt-ZnO/CNT
}

\author{
M MUJAHID \\ Department of Physics, Faculty of Science, University of Tabuk, Tabuk, P.O. 741, Tabuk 71491, Saudi Arabia
}

MS received 21 September 2014; accepted 29 January 2015

\begin{abstract}
This paper deals with synthesis of $\mathrm{ZnO}$ doped with different concentrations of platinum (Pt) and its deposition on the surface of multi-walled carbon nanotube (MWCNT). The synthesized nanocomposite material was characterized by standard analytical techniques like X-ray diffraction (XRD), UV-vis spectroscopy, scanning electron microscopy, transmission electron microscopy and energy-dispersive spectroscopy. The XRD analysis confirms two things; first, synthesized nanocomposite shows no impurity peaks indicating products being crystalline in nature, second, the phase structure of composite remains unchanged during doping of Pt into $\mathrm{ZnO}$ crystal. Results indicate that the incorporation of dopant into $\mathrm{ZnO}$ coated on the surface of MWCNT was found to shift the fundamental absorption edge towards the longer wavelength side. The impedance analysis was carried out to distinguish between the grain and grain boundary contributions to the system. The dielectric property was strongly affected by increasing the dopant concentration. The dielectric constant $(\varepsilon)$ and dielectric loss $(\tan \delta)$ factors decrease with the increase in frequency only upto a certain limit. The a.c. conductivity also increases with the increase in frequency.
\end{abstract}

Keywords. Pt-ZnO/CNT nanocomposite; dielectric constant; dielectric loss; a.c. conductivity.

\section{Introduction}

Zinc oxide $(\mathrm{ZnO})$ and titanium oxide $\left(\mathrm{TiO}_{2}\right)$ have received much more attention in the past due to their photocatalytic ability like air purification and water disinfection. ${ }^{1-4}$ The disadvantage of these materials is that they can use UV light only for their excitation due to large band gap energy. Hence they are unable to use the visible-light source. Therefore, scientists around the world are actively engaged in extending their optical response from UV to visible region by doping of these materials with metal or nonmetal or co-doped nonmetal or with other compounds. $\mathrm{ZnO}$ is found to be more acceptable semiconductor due to its distinguish features, naming few like it is not only an n-type low-cost semiconductor having band gap energy of $3.37 \mathrm{eV}$ at room temperature but also have a wurtzite structure. ${ }^{5}$ It is nontoxic and chemical stable. This material has got wide applications in areas like solar cells, ${ }^{6}$ varistors, ${ }^{7}$ ultraviolet light emitters ${ }^{8}$ and piezoelectric and transducers. ${ }^{9} \mathrm{ZnO}$ shows superior performance in absorption of UV light as compared with $\mathrm{TiO}_{2}{ }^{10}$

Researchers have been reported many methods for the synthesis of metal-doped $\mathrm{ZnO}$ nanoparticles. ${ }^{11-15}$ Among them, $\mathrm{ZnO}$ prepared by the sol-gel process has attracted considerable attention because of its simplicity and the fine

\footnotetext{
*Author for correspondence (mujahidm72@gmail.com)
}

crystalline quality. $\mathrm{ZnO}$ is doped with various metals or nonmetal in order to shift its absorbance band towards higher wavelength of visible light. ${ }^{16-18}$ Literature survey reveals that the doping into the $\mathrm{ZnO}$ lattice can be easily done by replacing $\mathrm{Zn}^{2+}$ atoms with the higher valency atom such as $\mathrm{Ga}, \mathrm{Al}$, In and La. ${ }^{19-25}$

In particular, synthesis of $\mathrm{Pt}-\mathrm{ZnO} /$ carbon nanotube (CNT) composite material is reported in literature using different methodologies. ${ }^{26-30}$ But systematic studies about its lowcost synthesis and quest about other electrical properties which will be very helpful to understand the study relating to the improvement of photocatalytic properties under UV and visible region, are absent. This study will also give a new perspective in the search of material suitable for highfrequency micro/nanoelectronics. Therefore we have synthesized Pt-doped $\mathrm{ZnO}$ nanocomposite with a uniform morphology and good structural stability by the sol-gel method using CNT as support.

\section{Experimental}

\subsection{Reagents and chemicals}

Multi-walled carbon nanotube (MWCNT), 3-chloroperbenzoic acid (3-CPBA), zinc acetate dihydrate, hexachloroplatinic acid were purchased from Sigma-Aldrich. Triton X-100, benzene, ammonium solution and 2-propanol were obtained from Merck. 


\subsection{Synthesis of Pt-ZnO/CNT composite}

MWCNT powder $(2.5 \mathrm{~g})$ was added in the solution of 3 -CPBA $(5 \mathrm{~g})$ in benzene $(200 \mathrm{ml})$ and refluxed at $180^{\circ} \mathrm{C}$ for $24 \mathrm{~h}$. The solid material so obtained was collected by centrifugation, washed several times with double distilled water and ethanol before being dried at $80^{\circ} \mathrm{C}$ for $6 \mathrm{~h}$. The oxidized MWCNT was added into the solution of zinc acetate dihydrate $(3.5 \mathrm{~g}$ ) and $2 \mathrm{~g}$ of surfactant (Triton X-100) in water $(100 \mathrm{ml})$. To this solution ammonia solution $(15 \mathrm{ml})$ was added drop wise into the solution under vigorous magnetic stirring and kept at $50^{\circ} \mathrm{C}$ for $10 \mathrm{~h}$. Hydrothermal treatment was carried out at $180^{\circ} \mathrm{C}$ for about $36 \mathrm{~h}$. After cooling the solution to room temperature, the precipitate obtained was filtered out, washed with double distilled water and ethanol, air dried and then calcined at $400^{\circ} \mathrm{C}$ for $16 \mathrm{~h}$ in nitrogen atmosphere to obtain the particle of nanosize. For doping of $\mathrm{ZnO}$ particle with Pt a known concentration of hexachloroplatinic acid (3-9\%, w/v) was added in the surfactant solution.

For the analysis of electrical properties a pellet of $13 \mathrm{~mm}$ in diameter and of thickness $1.8 \mathrm{~mm}$ was made by applying pressure up to $7 \mathrm{t} \mathrm{cm}^{-2}$ on the powder sample.

\subsection{Apparatus}

The structural characterization of undoped $\mathrm{ZnO} / \mathrm{CNT}$ and doped $\mathrm{ZnO} / \mathrm{CNT}$ nanocomposite were performed by X-ray diffraction (XRD) (Rigaku Miniflex II) in the $2 \theta$ range of 20$80^{\circ}$ with $\mathrm{CuK}_{\alpha}$ radiations $(\lambda=1.5418 \AA$ ) operated at a voltage of $30 \mathrm{kV}$ and current of $15 \mathrm{~mA}$. The UV-vis spectra of liquid samples were recorded using Shimadzu UV-vis spectrophotometer (Model 1601). The morphology and size were observed by scanning electron microscopy (SEM) (Inspect S50) and transmission electron microscopy (TEM) (JEOL 3010). Elemental composition were carried out by energydispersive spectroscopy (EDS) attached to SEM. Electrical properties were measured using computer-controlled LCR meter analyzer (Model Agilent E4982A).

\section{Results and discussion}

\subsection{XRD analysis}

The XRD analysis of undoped $\mathrm{ZnO} / \mathrm{CNT}$ and doped $\mathrm{ZnO} / \mathrm{CNT}$ composite material calcinated at $400^{\circ} \mathrm{C}$ for $16 \mathrm{~h}$ was analysed and shown in figure 1 . Pt-ZnO/CNT composite material showed no impurity peaks, indicating products being in crystalline nature. These results indicate that the phase structure remains unchanged during doping of Pt.

It is well known that the dopant can enter the $\mathrm{ZnO}$ lattice either interstitially or it can act as substitutional defect. The properties such as crystal structure, electronegativity, relative valency and atomic size decides substitution if they match closer to the $\mathrm{ZnO}$ lattice. In the present case the ionic radius of $\mathrm{Pt}^{4+}(0.076 \mathrm{~nm})$ is lesser than that of $\mathrm{Zn}^{+}(0.088 \mathrm{~nm})$. Therefore, these dopants act as interstitial defect.

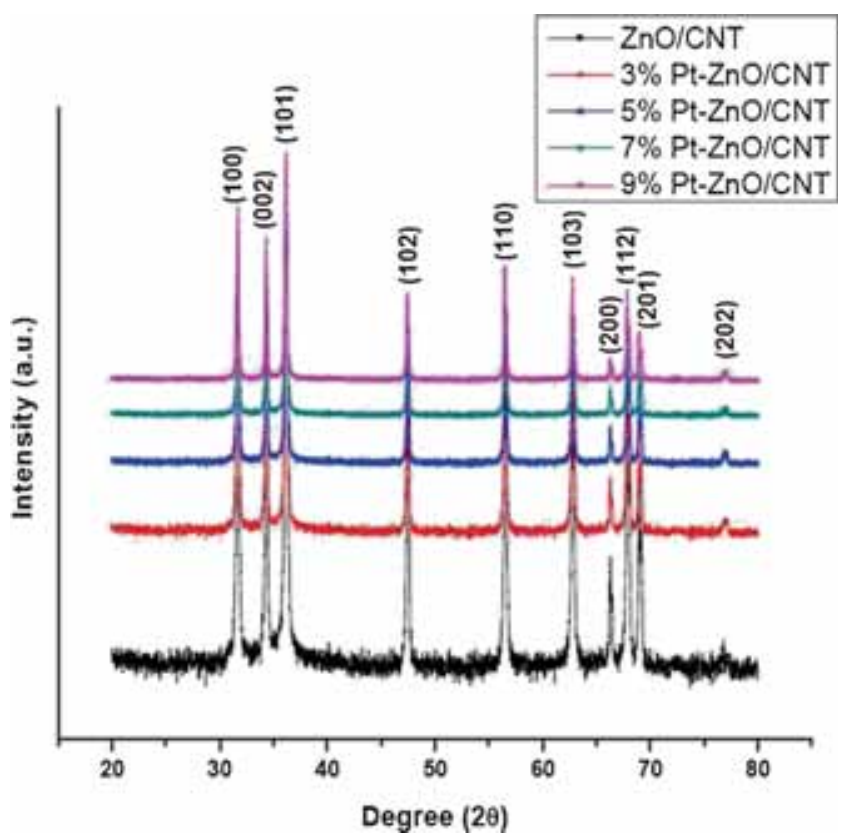

Figure 1. $\mathrm{XRD}$ patterns of $\mathrm{ZnO} / \mathrm{CNT}(\mathbf{A}), 3 \% \mathrm{Pt}-\mathrm{ZnO} / \mathrm{CNT}(\mathbf{B})$, 5\% Pt-ZnO/CNT (C), 7\% Pt-ZnO/CNT (D) and 9\% Pt-ZnO/CNT (E). Calcination temp: $400^{\circ} \mathrm{C}$, calcination time: $16 \mathrm{~h}$.

Table 1. Crystallite size of $\mathrm{Pt}-\mathrm{ZnO} / \mathrm{CNT}$ with different concentrations of dopants. Calcination temp: $400^{\circ} \mathrm{C}$, calcination time: $16 \mathrm{~h}$.

\begin{tabular}{lcc}
\hline S. no. & $\begin{array}{c}\text { Dopant } \\
\text { concentration }(\mathrm{Pt} \%)\end{array}$ & $\begin{array}{c}\text { Crystallite } \\
\text { size }(\mathrm{nm})\end{array}$ \\
\hline 1 & 0 & $24 \pm 0.5$ \\
2 & 3.0 & $18 \pm 0.5$ \\
3 & 5.0 & $16 \pm 0.5$ \\
4 & 7.0 & $14 \pm 0.5$ \\
5 & 9.0 & $14 \pm 0.5$ \\
\hline
\end{tabular}

The average hexagonal wurtzite crystallite size of doped and undoped $\mathrm{ZnO}$ nanoparticles was determined by the Scherrer equation ${ }^{31}$

$$
D=\frac{k \lambda}{\beta \cos \theta},
$$

where $D$ is the crystallite size, $k$ the shape factor, $\lambda$ the wavelength, $\theta$ the diffraction angle and $\beta$ the full-width at halfmaximum (FWHM). Table 1 shows the mean size of the crystallites in samples which were estimated by the FWHM of the XRD peak (101) using the Scherrer equation (1). The average crystallite sizes were found to be $17.2 \mathrm{~nm}$. Crystal phase, crystal size and crystallinity of $\mathrm{ZnO}$ have a great influence on its photocatalysis properties. It can be seen from the table that the crystallite size was found to decrease (from 24 to 6 $\mathrm{nm}$ ) upto certain limits ( $7 \%$ doping of $\mathrm{Pt}$ ) and then remain almost constant (14 nm) with the increase in Pt concentration as a dopant. This could be explained on the basis of the fact that the addition of dopant may hinder the growth of $\mathrm{ZnO}$ particle to some degree due to the formation of $\mathrm{Pt}-\mathrm{O}-\mathrm{Zn}$ on the surface of the doped samples. ${ }^{32}$ 


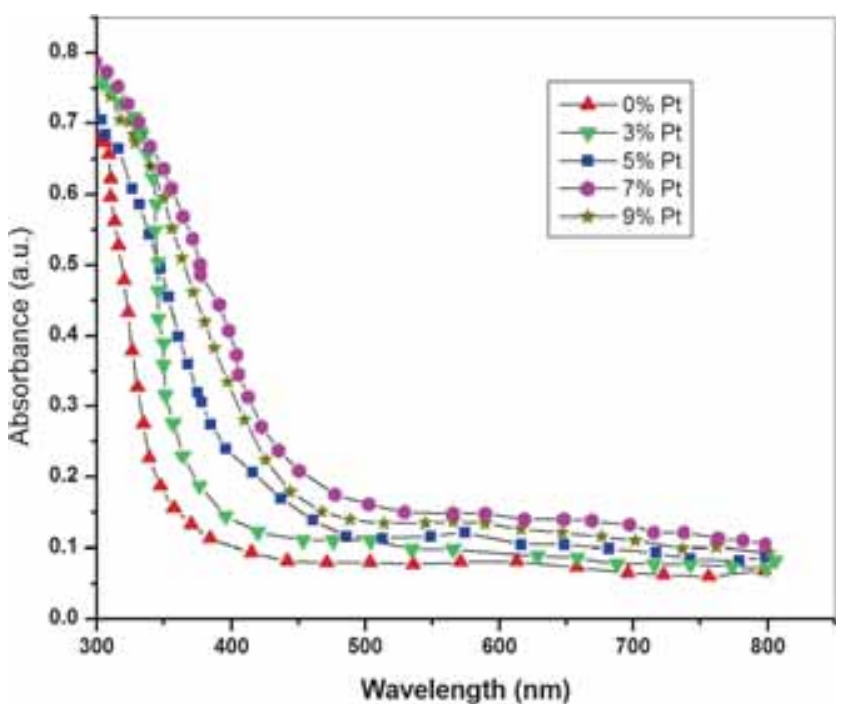

Figure 2. Absorption spectra of $\mathrm{Pt}-\mathrm{ZnO} / \mathrm{CNT}$ with different concentrations of dopant $(\mathrm{Pt})$. Calcination temp: $400^{\circ} \mathrm{C}$, calcination time: $16 \mathrm{~h}$.

Table 2. Band gap energy of Pt-ZnO/CNT with different concentrations of dopants. Calcination temp: $400^{\circ} \mathrm{C}$, calcination time: $16 \mathrm{~h}$.

\begin{tabular}{lcc}
\hline S. no. & $\begin{array}{c}\text { Dopant } \\
\text { concentration }(\mathrm{Pt} \%)\end{array}$ & $\begin{array}{c}\text { Band } \\
\text { gap }(\mathrm{eV})\end{array}$ \\
\hline 1 & 0 & $3.3 \pm 0.1$ \\
2 & 3.0 & $3.2 \pm 0.1$ \\
3 & 5.0 & $2.8 \pm 0.1$ \\
4 & 7.0 & $2.5 \pm 0.1$ \\
5 & 9.0 & $2.6 \pm 0.1$ \\
\hline
\end{tabular}

\subsection{UV-vis absorption spectra}

In order to calculate the band gap energy, UV-vis spectroscopic techniques are being used. Figure 2 shows the UVvis absorption spectra of liquid samples of $\mathrm{Pt}-\mathrm{ZnO} / \mathrm{CNT}$. Absorption edge, which is decided by the intercept on the wavelength axis for a tangent drawn on the absorption spectra of all the samples are found to be $375 \mathrm{~nm}$ ( $0 \%$ doping of $\mathrm{Pt}), 400 \mathrm{~nm}$ (3\% doping of Pt), $460 \mathrm{~nm}$ (5\% doping of Pt), $490 \mathrm{~nm}$ (7\% doping of Pt) and $480 \mathrm{~nm}$ (9\% doping of Pt). Thus, the incorporation of dopant into $\mathrm{ZnO}$ coated on CNT has been found to shift the fundamental absorption edge from UV region $(\lambda<387 \mathrm{~nm})$ to the visible region $(390-750 \mathrm{~nm})$ and towards longer wavelength (red shift) side.

With the obtained wavelength $(\lambda)$ from UV-vis absorption spectra, the band gap energies $\left(E_{\mathrm{g}}\right)$ of undoped and Pt$\mathrm{ZnO} / \mathrm{CNT}$ composite material were calculated using equation (2) and the results are depicted in table 2

$$
E_{\mathrm{g}}=\frac{h c}{\lambda},
$$

where $h$ is Planck's constant $\left(6.634 \times 10^{-34} \mathrm{~J} \mathrm{~s}\right)$ and $c$ the speed of light $\left(3 \times 10^{8} \mathrm{~m} \mathrm{~s}^{-1}\right)$.

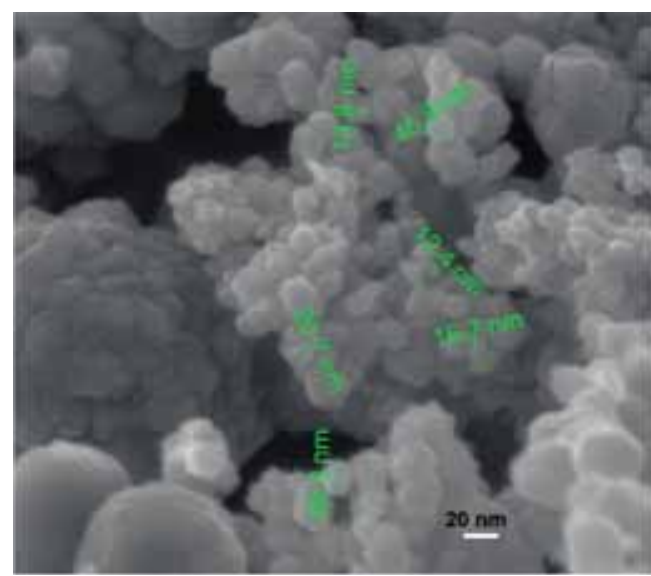

Figure 3. SEM images of $\mathrm{ZnO}$, calcination temp: $400^{\circ} \mathrm{C}$, calcination time: $16 \mathrm{~h}$.

The corresponding $E_{\mathrm{g}}$ values with due consideration of errors were found to be $3.3,3.2,2.8,2.5$ and $2.6 \mathrm{eV}$. Thus, the $E_{\mathrm{g}}$ values of the Pt-ZnO/CNT composite material were found to be smaller than that of pure $\mathrm{ZnO}(3.37 \mathrm{eV})$. This indicates that photocatalyst Pt-ZnO/CNT material would exhibit strong photocatalytic activity under solar light irradiation. Description of equation (2) is consistent with the reported result of Kashif et al. ${ }^{32}$

In addition, we also find that the incorporation of dopant into $\mathrm{ZnO}$ coated on CNT has been found to decrease the $E_{\mathrm{g}}$ value upto $7 \%$ loading of Pt. ${ }^{33,34}$ The $E_{\mathrm{g}}$ value increases at higher concentration of dopant (Pt 9\%). This may be due to the deposition of the metal on the photocatalyst which covered the surface of $\mathrm{ZnO} .{ }^{35}$ With the increase in the amount of doping, the density of states of these dopants increases and forms a continuum of states just like the bands and effectively increases the band gap.

\subsection{SEM analysis}

Figure 3 shows the SEM image of the hexagonal crystal structure of $\mathrm{ZnO}$ calcined at $400^{\circ} \mathrm{C}$ for $16 \mathrm{~h}$. The average particle size of $\mathrm{ZnO}$ was found to be $20.7 \mathrm{~nm}$ that seems to be consistent with the value estimated using the Scherrer equation.

\subsection{TEM analysis}

Figure 4a shows the image of TEM measurement. This figure presents the morphology of one of the sample doped with $9 \%$ concentration of $\mathrm{Pt}$ onto $\mathrm{ZnO} / \mathrm{CNT}$ composite material. The presence of CNT in the composite material can be seen in this image. We can also find black-grey circular dots in contrast, confirming the presence of Pt-doped $\mathrm{ZnO}$ material.

Additionally, the Debye rings can also be shown in figure $4 b$ that suggests a series of the diffraction rings, 

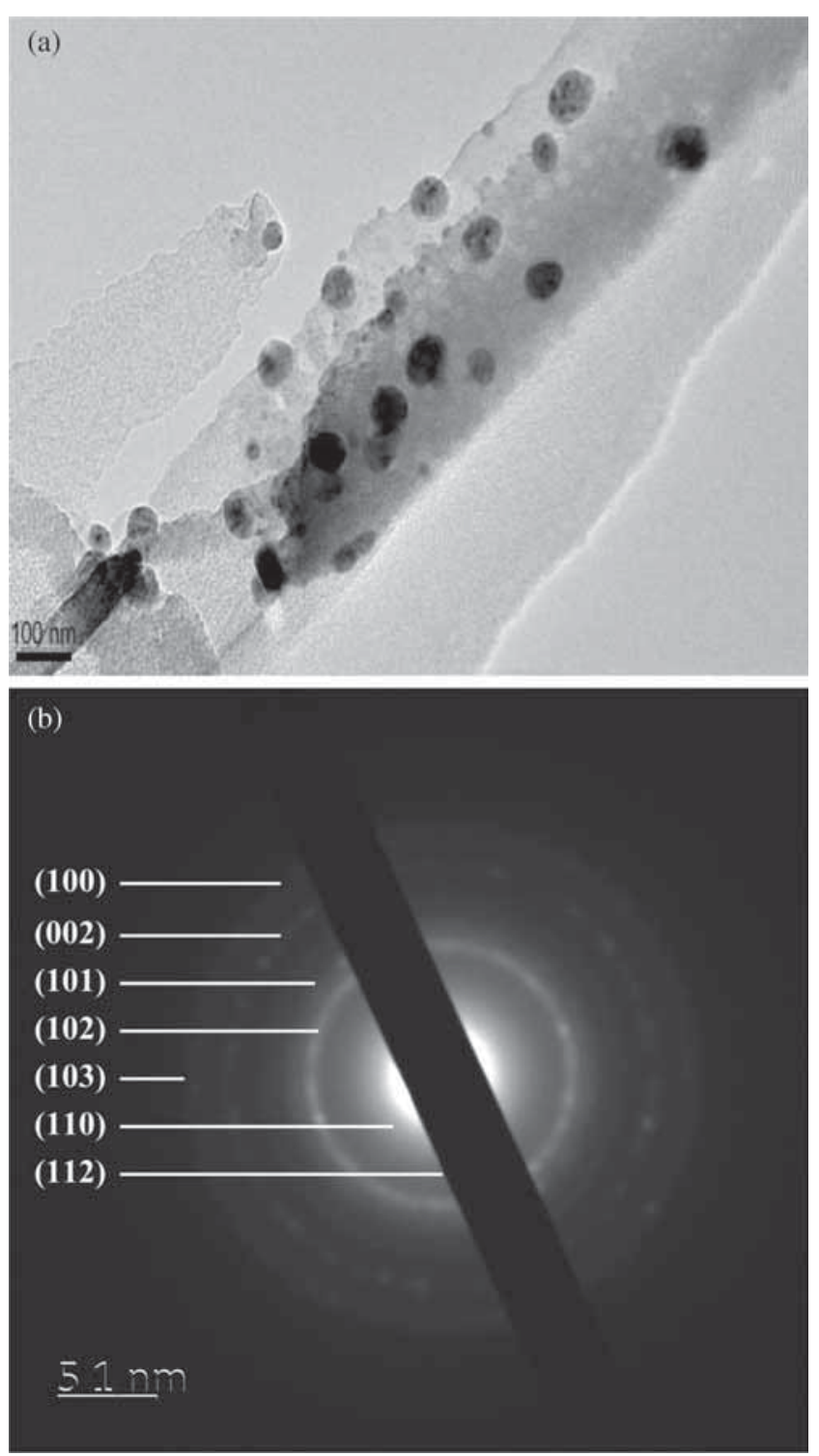

Figure 4. TEM images of $\mathrm{Pt}-\mathrm{ZnO} / \mathrm{CNT}$ composite material (a), calcination temp: $400^{\circ} \mathrm{C}$, calcination time: $16 \mathrm{~h}$. Diffraction plane of composite (b).

revealing the hexagonal wurtzite crystal structure of $\mathrm{ZnO}$. The corresponding crystal planes of $\mathrm{ZnO}$ are found to be (100), (002), (101), (102), (103), (110) and (112), which are in good agreement with the result obtained from XRD.

\subsection{EDS analysis}

To confirm the Pt doping into ZnO EDS spectra was recorded in the binding energy region of $0-19 \mathrm{keV}$ which is shown in figure 5 . The signals from the spectrum revealed the presence of $\mathrm{Zn}, \mathrm{O}$ and $\mathrm{Pt}$ at $0.5,1.0$ and $1.75 \mathrm{keV}$, respectively. The atomic percentage of $\mathrm{Zn}, \mathrm{O}$ and $\mathrm{Pt}$ were found to be $31.36 \%$, $59.32 \%$ and $9 \%$, while that for other elements were found to be $0.32 \%$. Other peak signifies the water-soluble elements of $\mathrm{Mg}, \mathrm{Ca}$ and $\mathrm{Na}$.

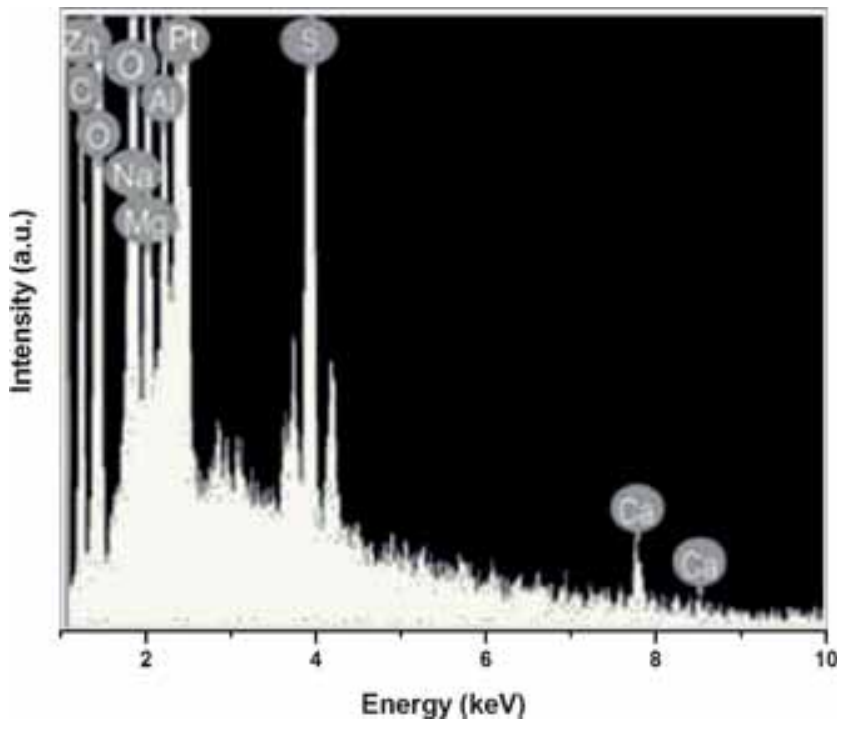

Figure 5. EDS spectra of $\mathrm{Pt}-\mathrm{ZnO} / \mathrm{CNT}$ composite material, calcination temp: $400^{\circ} \mathrm{C}$, calcination time: $16 \mathrm{~h}$.

\subsection{Electrical properties}

3.6a Impedance analysis: The impedance spectroscopy (IS) is the new approach to analyse electrical properties of materials and their interfaces. The dynamics of bound or mobile charge at the interfacial regions of any material can be studied using this technique. The impedance analysis of Pt$\mathrm{ZnO} / \mathrm{CNT}$ nanoparticles has been studied over a wide range of frequencies at room temperature using IS technique. Electrical conductivity of a system is strongly influenced by many parameters like crystallographic structure, mechanical properties, compositional chemistry, charging and polarization. When such system is kept under applied potential difference, each and every interface gets polarized in its unique way. A polarized region changes with time when the applied voltage is reversed. This is the unique characterization of the type of interface.

IS technique is widely used to separate the resistive and capacitive components of electrical parameters and hence provides a clear picture of the features of the material. When the impedance data of materials having capacitive and resistive components are plotted in a complex plane plot, they appear in the form of a sequence of semicircles representing electrical phenomenon due to bulk grain material, grain boundary and interfacial phenomenon if any. Generally, the grains are effective in high frequency region while the grain boundaries are effective in low frequency region. Thus the semicircle appearing in the high frequency region corresponds to grain contribution while in low frequency region corresponds to the grain boundary contribution.

In order to find out the maximum possible information about the material, the impedance analysis techniques have been used. ${ }^{36}$ For impedance analysis, each semicircular arc can be fitted by an equivalent circuit having a resistor $(R)$ and a capacitor $(C)$ which is connected in parallel. The equivalent 


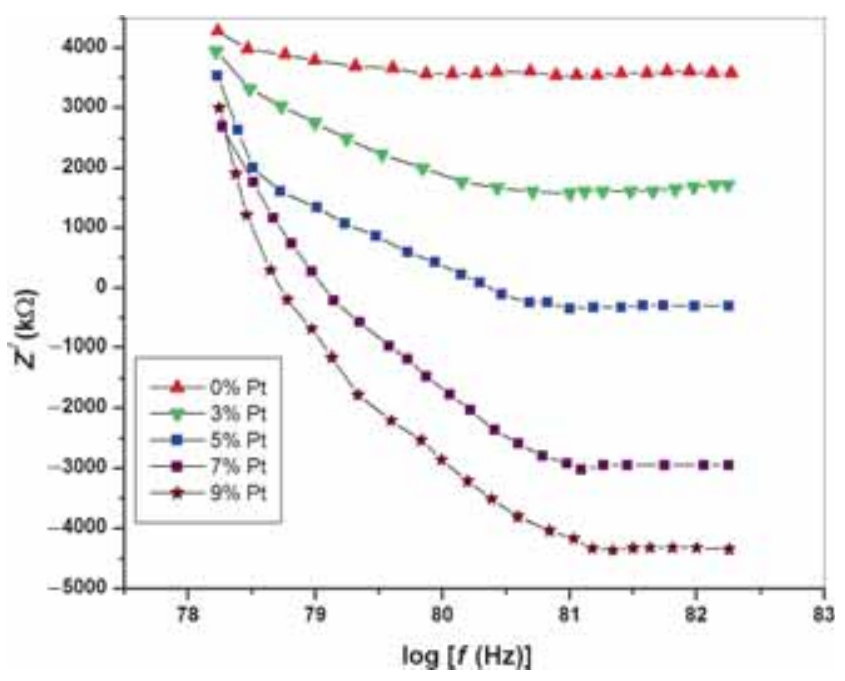

Figure 6. Variation in real impedence $Z^{\prime}$ as a function of frequency and Pt compositions.

circuit consisting of series of connected parallel resistance $R$ and capacitance $C$ elucidate the impedance spectra. The complex impedance is the sum of real and imaginary parts, represented as

$$
Z^{*}=Z^{\prime}+\mathrm{j} Z^{\prime \prime},
$$

where $Z^{\prime}$ and $Z^{\prime \prime}$ are given by the following relations:

$$
\begin{aligned}
& Z^{\prime}=\frac{R_{\mathrm{g}}}{1+\left(\varpi_{\mathrm{g}}^{2} C_{\mathrm{g}}^{2} R_{\mathrm{g}}^{2}\right)}+\frac{R_{\mathrm{gb}}}{1+\left(\varpi_{\mathrm{gb}}^{2} C_{\mathrm{gb}}^{2} R_{\mathrm{gb}}^{2}\right)}, \\
& Z^{\prime \prime}=\frac{R_{\mathrm{g}}^{2} \varpi_{\mathrm{g}} C_{\mathrm{g}}}{1+\left(\varpi_{\mathrm{g}}^{2} C_{\mathrm{g}}^{2} R_{\mathrm{g}}^{2}\right)}+\frac{R_{\mathrm{gb}}^{2} \varpi_{\mathrm{gb}} C_{\mathrm{gb}}}{1+\left(\varpi_{\mathrm{gb}}^{2} C_{\mathrm{gb}}^{2} R_{\mathrm{gb}}^{2}\right)},
\end{aligned}
$$

where $R_{\mathrm{g}}, R_{\mathrm{gb}}, C_{\mathrm{g}}$ and $C_{\mathrm{gb}}$ are the resistance and capacitance of the grain and grain boundary, respectively, while $\varpi_{\mathrm{g}}$ and $\varpi_{\mathrm{gb}}$ are the frequencies at the peaks of the semicircles for grain and grain boundary, respectively.

The frequency at the semicircle maxima

$$
\omega_{\max }=2 \pi f_{\max }=(R C)^{-1}=\tau^{-1},
$$

where $\tau=R C$ is the time constant of the $R C$ element.

Figures 6 and 7 show the real part $\left(Z^{\prime}\right)$ and imaginary part $\left(Z^{\prime \prime}\right)$ of impedances with frequency at different concentrations of $\mathrm{Pt}$ in $\mathrm{ZnO} / \mathrm{CNT}$ composite material. The result showed that $Z^{\prime}$ and $Z^{\prime \prime}$ decrease with the increase in frequency due to the space-charge contribution. ${ }^{37}$ With increase of doping concentration, $Z^{\prime}$ decreases because of the increase of flow of electrons across the photo-anode. $Z^{\prime \prime}$ shows opposite trend, i.e., with the increase of doping concentration $Z^{\prime \prime}$ increases because conduction of electrons is rare. ${ }^{38}$ At low frequency the complex impedance values are higher which indicate the larger polarization, which on further increase in frequency shows independent behaviour.

Al-Hardan et $\mathrm{l}^{39}$ in the year 2011 showed that IS analysis is very useful to study the undoped and Cr-doped gas sensor under different oxygen concentrations. They found that

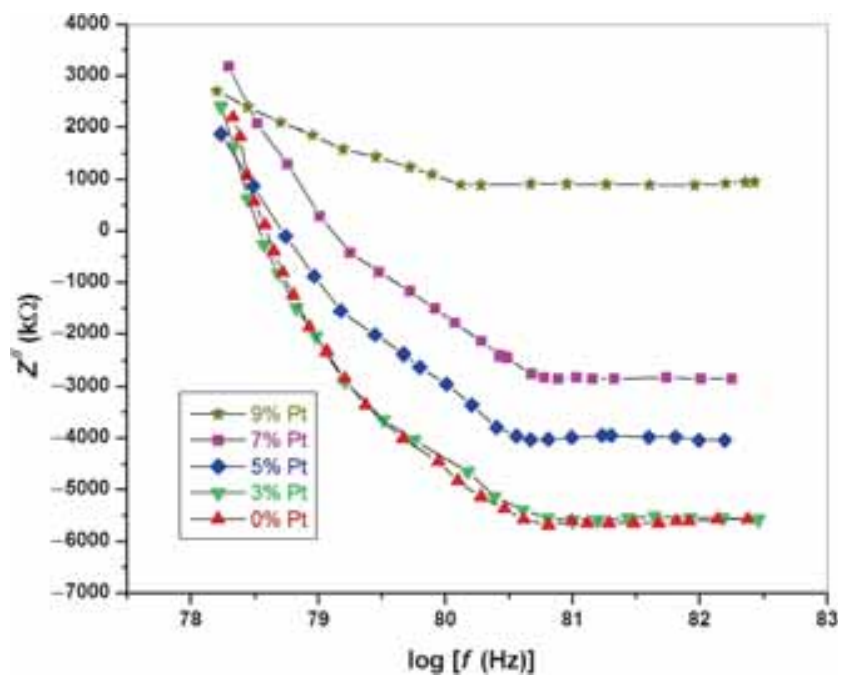

Figure 7. Variation in imaginary impedence $Z^{\prime \prime}$ with frequency and Pt compositions.

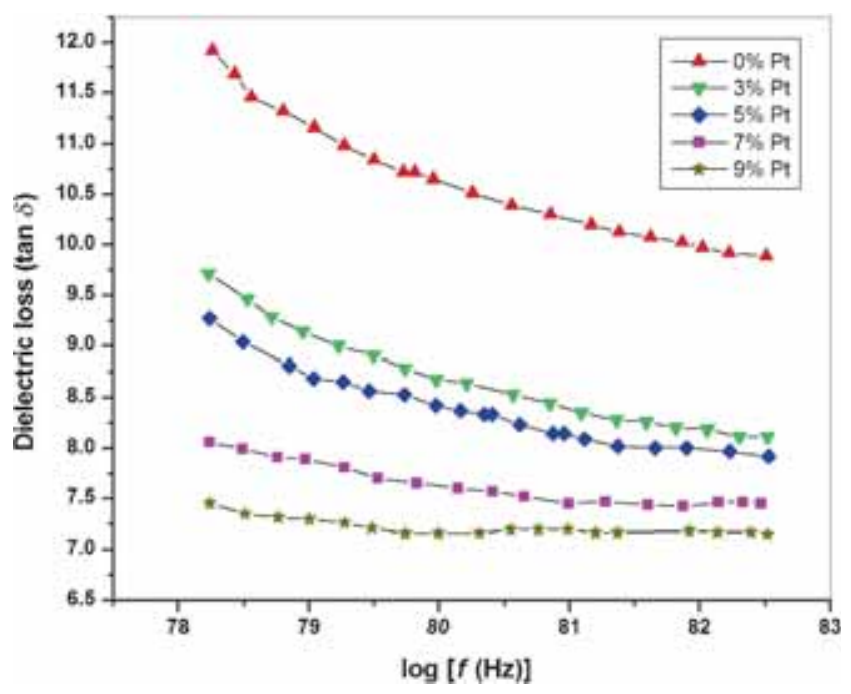

Figure 8. Variation in dielectric loss with frequency at different compositions of $\mathrm{Pt}$.

resistance (nearly $2 \mathrm{M} \Omega$ at different concentrations of oxygen) and capacitance (nearly $90 \mathrm{pF}$ at different concentrations of oxygen) due to grain boundaries play a significant contribution in the characteristics of the gas sensor. Similarly Hong and $\mathrm{Kim}^{40}$ in the year 2004 found that IS analysis is an effective tool for explanation of the effect of $\mathrm{Mn}_{3} \mathrm{O}_{4}$ doping on the bulk and grain boundary characteristics of $\mathrm{ZnO}-\mathrm{Bi}_{2} \mathrm{O}_{3}-\mathrm{Sb}_{2} \mathrm{O}_{3}$ system. They found that activation energy of $0.33 \mathrm{eV}$ for bulk trap level of Mn-doped sample and that for $0.40 \mathrm{eV}$ for interface trap level. Chiu and $\mathrm{Wu}^{41}$ in 2012 also found that electrical resistance plays a significant contribution for the existence of $\mathrm{Li}$ ions in the grain of $\mathrm{ZnO}$.

3.6b Dielectric studies: To find out the material suitable for high frequency microelectronic device application 


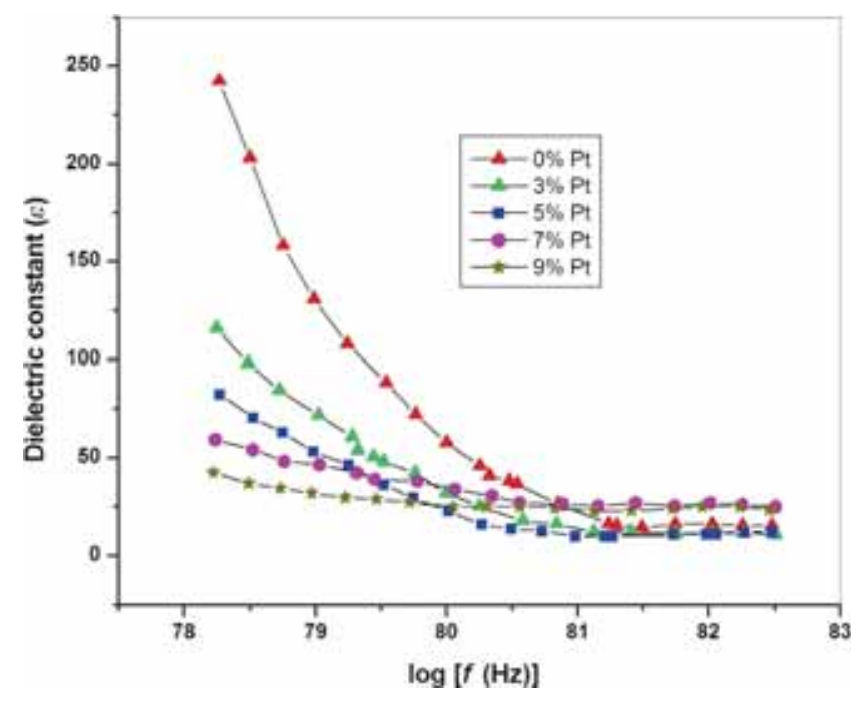

Figure 9. Variation in dielectric constant with frequency for different compositions of Pt.

dielectric studies have been carried out. The variation of dielectric constant $(\varepsilon)$ and tangent loss $(\tan \delta)$ with frequency for various concentrations of $\mathrm{Pt}$ in $\mathrm{Pt}-\mathrm{ZnO} / \mathrm{CNT}$ are as shown in figures 8 and 9 , respectively, at room temperature. The behaviours of these figures are found in the same pattern as described by Song et $a l^{42}$ in the study of dielectric properties of MWCNTs/ZnO wax-matrix composites for EMI shielding. The dielectric properties of a material depend upon different types of polarization, viz., dipolar, electronic, atomic and space-charge polarization.

The result of figures 8 and 9 shows that the values of $\varepsilon$ and $\tan \delta$ decreases with an increase in frequency. At low frequency, the dielectric constant is high due to the accumulation of charge at the grain boundary, and at the interface of electrode sample and electrode which is also called space-charge polarization. ${ }^{43}$ As the frequency increases, the dielectric constant decreases due to the gradual diminishing of the space-charge polarization, indicating the electronic and atomic contribution domination. The dielectric constant is independent at higher frequency which indicates the domination of electronic and atomic contribution. ${ }^{44}$

Another reason can be attributed on the basis of the Maxwell-Wagner interfacial model. According to this model, ${ }^{45}$ a dielectric medium consist of double layers having well conducting grains that are separated by poorly conducting grain boundaries. When the external electric field is applied, the charge carriers can easily migrate the grains but they were accumulated at the grain boundaries resulting in large polarization and high dielectric constant value. The higher value of dielectric constant is also due to inhomogeneous dielectric structure which may be due to porosity and grain structure. The dielectric property decreases with the increase in frequency and then shows independent behaviour due to the fact that beyond a certain frequency of external field the hopping between metal ions cannot follow the alternating field.

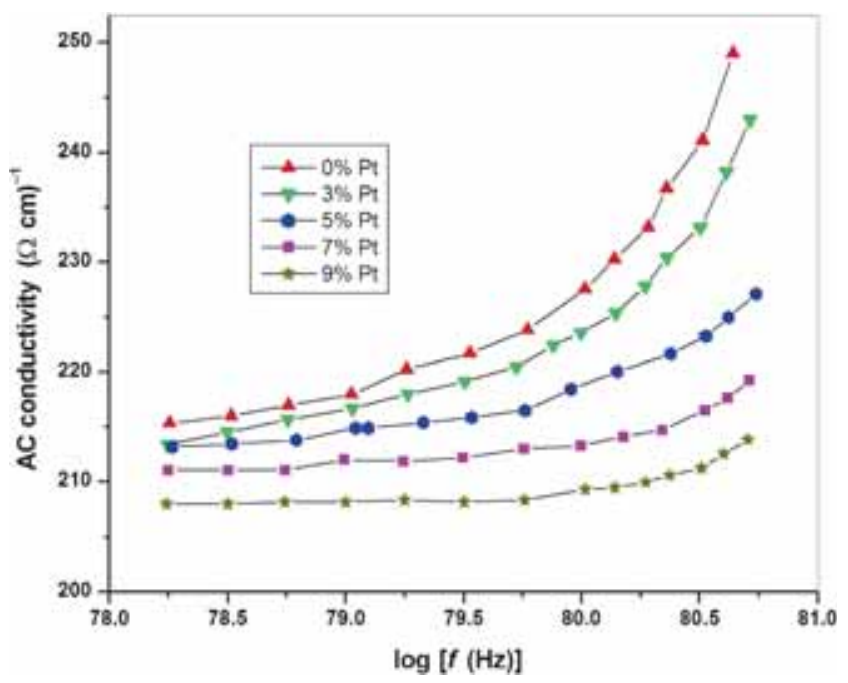

Figure 10. Variation of a.c. conductivity with frequency for different compositions of Pt.

3.6c a.c. Conductivity: Figure 10 shows the variation of a.c. conductivity with frequency for different concentrations of $\mathrm{Pt}$ in $\mathrm{Pt}-\mathrm{ZnO} / \mathrm{CNT}$ samples at room temperature.

The overall conductivity is the summation of a.c. conductivity and d.c. conductivity which is given by

$$
\sigma=\sigma_{\mathrm{o}}(T)+\omega \varepsilon_{\mathrm{o}} \varepsilon_{\mathrm{r}} \tan \delta,
$$

where $\omega$ is the angular frequency, $\varepsilon_{0}$ the permittivity of free space, $\sigma_{0}(T)$ the d.c. conductivity and independent of frequency and $\omega \varepsilon_{0} \varepsilon_{\mathrm{r}} \tan \delta$ the a.c. conductivity, which depends on frequency.

From the figure it is clear that the conductivity increases with the increase in frequency of the applied a.c. field. This is due to the fact that on increasing the frequency, the electron hopping frequency enhances. It also shows that the a.c. conductivity decreases with the increase in dopant concentration due to the decrease in the particle size and increase in the ratio of the surface volume. It happens due to the corresponding occurrence of scattering. ${ }^{46}$ Another reason can be attributed to the fact that the dopants can introduce the defect ions in $\mathrm{ZnO}$ lattice. These defects may lead to segregate at the grain boundaries due to the diffusion process resulting from sintering and cooling processes. Therefore, on increasing the dopant concentration, the concentration of defect ions also increases hence facilitates the formation of grain boundary defect barrier which may lead to the blockage of flow of charge carriers resulting into the decreases in the conductivity of the system. ${ }^{47}$

\section{Conclusion}

This study reveals that the doping of Pt into $\mathrm{ZnO}$ loaded on CNT shifts the position of its fundamental absorption edge towards the longer wavelength, i.e., red shift and reduces its band gap energy in order to absorb the energy from major portion of visible light. The XRD analysis shows no 
change in crystal structure of $\mathrm{ZnO}$ after doping with different concentrations of $\mathrm{Pt}$, indicating single-phase polycrystalline material. The SEM analysis reveals the hexagonal crystal of $\mathrm{ZnO}$ while TEM measurement presents the morphology of Pt-ZnO/CNT composite material. EDS analysis is carried out to check the deposition of Pt nanoparticle. In the low frequency region the dielectric constant decreases with the increase in frequency, whereas in the high frequency region, it shows the frequency-independent behaviour and at high frequency dielectric loss is constant so it can be used for high frequency devices. Pt-ZnO/CNT also shows that a high dielectric constant and low dielectric loss with frequency implying that the material is suitable for microelectronic device applications. As the frequency increases the magnitude of complex impedance decreases resulting in the increase in a.c. conductivity.

\section{Conflict of interest}

We confirm that this article content has no conflicts of interest.

\section{References}

1. Blake D M 2001 Bibliography of work on the photocatalytic removal of hazardous compounds from water and air (Colorado, USA: National Renewal Energy Laboratory)

2. Haque M M, Muneer M and Bahnemann D W 2006 Environ. Sci. Technol. 404765

3. Paschoalino F C S, Paschoalino M P, Jordão E and Wilson De Figueiredo J 2012 Open J. Phys. Chem. 2135

4. Ba-Abbad M M, Kadhum H A A, Mohamad A B, Takriff M S and Sopian K 2013 J. Alloys Compd. 55063

5. Meyer B K, Alves H, Hofmann D M, Kriegseis W, Forster D, Bertram F, Christen J, Hoffmann A, Straßburg M, Dworzak M, Haboeck U and Rodina A V 2004 Phys. Status Solidi B 241 231

6. Hembram K, Sivaprahasam D and Rao T N 2011 J. Eur. Ceram. Soc. 311905

7. Liu Z, Liu C, Ya J and Lei E 2011 Renew. Energy 361177

8. Cheng H C, Chen C F and Tsay C Y 2007 Appl. Phys. Lett. 90 012113

9. Sahay P P and Nath R K 2008 Sens. Actuators B 133222

10. Shinde S S, Shinde P S, Bhosale C H and Rajpure K Y $2011 J$. Photochem. Photobio. B 104425

11. Du S F, Tian Y J, Liu H D, Liu J and Chen Y F 2006 J. Am. Ceram. Soc. 892440

12. Zhang W H, Zhang W D and Zhou J F 2010 J. Mater. Sci. 45 209

13. Serier H, Gaudon M and Menetrier M 2009 Solid State Sci. 11 1192

14. Suwanboon S, Amornpitoksuk P and Bangrak P 2011 Ceram. Int. 37333

15. Meng F, Yin J, Duan Y Q, Yuan Z H and Bie L J 2011 Sens. Actuators B 156703

16. Wang H, Baek S, Song J, Lee J and Lim S 2008 Nanotechnology 19075607

17. Zhi M, Zhu L, Ye Z, Wang F and Zhao B 2005 J. Phys. Chem. B 10923930
18. Wang R C, Liu C P, Huang J L and Chen S J 2006 Appl. Phys. Lett. 88023111

19. Serier H, Gaudon M and Menetrier M 2009 Solid State Sci. 11 1192

20. Verma A, Khan F, Kar D, Chakravarty B C, Singh S N and Husain M 2010 Thin Solid Films $\mathbf{5 1 8} 2649$

21. Ogi T, Hidayat D, Iskandar F, Purwanto A and Okuyama K 2009 Adv. Powder Technol. 20203

22. Chunqiao G, Changsheng X, Mulin H, Yanghai G, Zikui B and Dawen Z 2007 Mater. Sci. Eng. B 14143

23. Maiyalagan T R and Das S J 2012 Mater. Sci. Semicond. Process. 15308

24. Anandan S, Vinu A, Lovely K L P S, Gokulakrishnan N, Srinivasu P, Mori T, Murugesan V, Sivamurugan V and Ariga K 2007 J. Mol. Catal. A: Chem. 266149

25. Korake P V, Dhabbe R S, Kadam A N, Gaikwad Y B and Garadkar K M 2014 J. Photochem. Photobiol. B: Biol. 130 11

26. Zhang Y, Sun X, Pan L, Li H, Sun Z, Sun C and Tay B K 2009 Solid State Ion 1801525

27. Chen H C, Lin S F and Huang K T 2014 Appl. Opt. 53 A242

28. Vyas R, Sharma S, Gupta P, Prasad A K, Tyagi A K, Sachdev K and Sharma S K 2012 Adv. Mater. Res. 585235

29. Xuejing W, Shuwen Y and Xiaobo L 2009 Chin. J. Chem. 27 1317

30. Ramar A, Soundappan T, Shen-Ming C, Rajkumar M and Ramiah S 2012 Int. J. Electrochem. Sci. 711734

31. Lin J, Yu J C, Lo D and Lam S K 1999 J. Catal. 183368

32. Kashif M, Hashim U, Ali M E, Foo K L and Usman Ali S M 2013 J. Nanomater. 2013478942

33. Stengl V, Bakardjieva S and Murafa N 2009 Mater. Chem. Phys. 114217

34. Stengl V and Bakardjieva S 2010 J. Phys. Chem. C 114 19308

35. Devi L G, Kottam N and Kumar S G 2009 J. Phys. Chem. C 1135593

36. Saif A A, Ajamal Z, Sauli Z and Poopalan P 2011 Mater. Sci. (Medziagotyra) 17186

37. Gafoor A K A, Thomas J, Mustafa M M and Pradyumnan P P 2011 J. Electron. Mater. 402152

38. Kim H-S, Lee C R, Lim J H, Lee K B, Thomas M, Arianna M, Moon S J, Baker R H, Yum J H, Mosar J E, Michael G and Park N G 2012 Sci. Rep. 2591

39. Al-Hadran N, Abdullah M J and Abdul Aziz A 2011 Appl. Surf. Sci. 2578093

40. Hong Y W and Kim J H 2004 Ceram. Int. 301307

41. Chiu K-C and Wu Y-H 2012 Adv. Mater. Res. 4151925

42. Song W-L, Cao M-S, Wen B, Hou Z-L, Cheng J and Yuan J 2012 Mater. Res. Bull. 471747

43. Liqiang J, Xiaojun S, Baifu X, Baiqi W, Weimin C and Hongganga F 2004 J. Solid State Chem. 1773375

44. Mangrola M H, Parmar B H, Pillai A S and Joshi V S 2012 Multi Discipl. Edu. Global Quest. 1138

45. Prodromakis T and Papavassiliou C 2009 Appl. Surf. Sci. 255 6989

46. Lin J-P and Wu J-M 2009 Scr. Mater. 60313

47. Azam A, Ahmad A S, Chaman M and Naqvi A H 2010 J. Appl. Phys. 108094329 